\title{
Reply to Comment on: Inherited Thrombophilia and Pregnancy Complications: Should We Test?
}

\author{
Deepa R.J. Arachchillage, MD ${ }^{1,2}$ Mike Makris, MD $^{3,4}$ \\ 1 Department of Haematology, Imperial College Healthcare National \\ Health Service Trust and Imperial College London, Hammersmith \\ Hospital, London, United Kingdom \\ 2 Department of Haematology, Royal Brompton Hospital, London, \\ United Kingdom \\ 3 Haemophilia and Thrombosis Centre, Royal Hallamshire Hospital, \\ Sheffield, United Kingdom \\ 4 Department of Infection, Immunity and Cardiovascular Disease, \\ University of Sheffield, Sheffield, United Kingdom
}

Semin Thromb Hemost 2019;45:555-556.

We would like to thank Dr. Ruiz-Arguelles ${ }^{1}$ for his letter to the editor suggesting that we omitted "sticky platelet syndrome," an inherited thrombophilic condition, from our paper on inherited thrombophilia testing in women with pregnancy complications. ${ }^{2}$ Our omission was deliberate and was not an oversight.

Before we can suggest that a woman with a pregnancy complication gets tested for an inherited thrombophilic disorder, it needs to be shown that the disorder (1) exists, (2) there is a good evidence for its mode of inheritance, (3) it is associated with pregnancy complications, and (4) a randomized controlled trial has shown that a beneficial treatment is available.

The arguments on whether the sticky platelet syndrome exists were discussed in a recent commentary in this journal by Favaloro and Lippi. ${ }^{3}$ We do not wish to recount the arguments as to whether this is a defined disorder or the extreme variation of normal platelet reactivity and we consider ourselves as agnostic. We accept that the disorder may be real but the evidence so far is not convincing enough for us. We do not accept that there is good evidence of its mode of inheritance. Had the inheritance for the disorder been clear, we would have expected next generation sequencing to have identified the molecular defect respon-
Address for correspondence Deepa R.J. Arachchillage, MD, Department of Haematology, Imperial College Healthcare NHS Trust and Imperial College London, Hammersmith Hospital, 4th Floor, Commonwealth Building, Du Cane Road, London W12 ONN, United Kingdom (e-mail: d.arachchillage@imperial.ac.uk).

sible for it by now, but this has not happened. We do not believe that there is irrefutable evidence that this syndrome is associated with pregnancy complications either. Even if we take the first three criteria as being true, no large prospective trial has shown a drug to be beneficial to women with this syndrome and pregnancy complications. Until evidence becomes available that satisfies all the above four criteria, we do not feel that testing for sticky platelet syndrome is indicated or appropriate in women with pregnancy complications.

Conflict of Interest

None.

\section{References}

1 Ruiz-Arguelles GJ. Comment on: inherited thrombophilia and pregnancy complications: should we test? Semin Thromb Hemost 2019;45(05):554-554

2 Arachchillage DRJ, Makris M. Inherited thrombophilia and pregnancy complications: should we test? Semin Thromb Hemost 2019;45(01):50-60

3 Favaloro EJ, Lippi G. Commentary: controversies in thrombosis and hemostasis part 2-does sticky platelet syndrome exist? Semin Thromb Hemost 2019;45(01):69-72
Issue Theme Editorial Compilation VII; Guest Editors: Emmanuel J. Favaloro, PhD, FFSc (RCPA), and Giuseppe Lippi, MD.
Copyright $\odot 2019$ by Thieme Medical Publishers, Inc., 333 Seventh Avenue, New York, NY 10001, USA. Tel: +1(212) 584-4662.
DOI https://doi.org/ 10.1055/s-0039-1692213. ISSN 0094-6176. 